\title{
The Effect of Internal Marketing Elements on Organizational Commitment of Health Workers (A Case of Ethiopia)
}

\author{
Yilma Geletu \\ Department of Marketing Management, College of Business and Economics, Hawassa University, PO box 05, \\ Hawassa, Ethiopia \\ $\mathrm{PhD}$ Fellow at Jonkoping International Business School, JU, Sweden
}

\begin{abstract}
Internal marketing has been taken as a tool that can positively influence organizational commitment of employees to consistently deliver quality service. However, not much is known about the effect of internal marketing on employee commitment in health care institutions especially in Ethiopian context. This study, therefore, attempts to examine the effect of internal marketing on organizational commitment in the case of health care institutions in Sidama Zone. A structured questionnaire was used to collect data. Respondents were selected using simple random sampling technique and data analyzed mainly using correlation and regression. The study established three dimensions of internal marketing comprising, vision, staff development, and reward. Together, these internal marketing dimensions had 15 items which predicted almost $73 \%$ of the variance in employee commitment.
\end{abstract}

Keywords: Internal marketing, organizational commitment health workers

JEL Classification: M10 - General

DOI: $10.7176 / \mathrm{JMCR} / 61-02$

Publication date:October $31^{\text {st }} 2019$

\section{INTRODUCTION}

In this chapter, background to the problem along with a brief description of the concept of internal marketing has been discussed. Specifically, the following points has been presented: background of the study, statement of the problem, objective of the study, research questions, scope of the study, and significance of the study.

\subsection{Background of the study}

From its beginning marketing has been seen as an important component of private business activities engaged in the sale of goods ( Kotler, 1967). However, in its later stages of evolution it has been adapted to the service sector (Berry \& Allen, 1977; Berry, 1980; Grönroos, 1980; Kotler \& Fox, 1985).

Internal marketing (IM) come forward in 1960s (Rafiq \& Ahmed, 2000) as a means to enhance quality of goods and services (Bennett \& Barkensjo, 2005). The basic rationale behind the concept of internal marketing is the idea that by satisfying employees as internal customers, organizations will build up their human asset and will be better positioned to fulfill the requirements of their external customers (Berry, 1980). This is based on the assumption that satisfying employees' needs will enhance their commitment thereby their performance.

"Internal Marketing means that the service firm must orient and motivate its customer contact employees and supporting service people to work as a team to provide customer satisfaction. Marketers must get everyone in the organization to be customer centered. In fact, internal marketing must precede external marketing." (Kotler \& Armstrong, 2008; 241-242). In other words, IM involves applying the basic marketing concept along with its mix elements to an organization's workers in which employees are treated as internal customers of the organization in order to advance corporate effectiveness (Berry, 1995). In this way, organizations can create customer oriented employees through a job and a work environment that motivates the employees to react favorably to the management's demands for customer orientation and interactive marketing performance (Gronroos, 1981).

Many organizations have been downsizing management levels in order to share responsibility and decision making down to lower levels that is closer to the external customer (Gilmore, 2000, cited in Carlos \& Ricardo, 2012), so organizations are appreciating employee as their most important asset. Thus, taking care of external customers can be realized only by giving care to workers. Such a practice is Internal Marketing (IM) (Hartline \& Bejou, 2004). Despite considerable research work on IM, its practical application is limited to few organizations. Moreover, the varied meaning of the concept of IM is a challenge for its implementation (Ahmed \& Rafiq, 2002). Due to relationship between IM and one of its outcomes - organizational commitment (Malhotra \& Mukherjee, 2004; Aburoub et al., 2011), the subject of this study is of research and academic foci. An elevated degree of IM improves the strategy of organizations in responding to their environmental pressures (Naude et al., 2003; Gounaris, 2006).

Health Care Institutions (HCIs) are establishments that provide health and related services to the community and exchange knowledge between researchers, practitioners, policy makers. Therefore, from the context of HCIs, 
internal marketing notifies that health workers are the first market and then patients are the second market. Service companies such as HCIs, thus, strive to achieve customer satisfaction through employee/health workers satisfaction. The assessment of internal marketing aspects and their effect on organizational commitment among health workers in HCIs makes sense especially in developing countries such as Ethiopia where there is a deep desire for better organizational performance, organizational citizenship behavior etc. all of which contributes positively to the improved health of the society and its developmental endeavor. Moreover, lack of rigorous research and publication about the association between internal marketing and organizational commitment on the context of Ethiopia makes this research timely and appropriate.

\subsection{Statement of the Problem}

The concept of Internal Marketing signifies the role of employees in achieving organization objectives. Employees are critical resources for any service organization. As quoted by Tesfaye, (2004), "the main assets of an organization/institution are its employees not the buildings, or the machines inside them (McShane \& Von Glinow, 2000)." Further, (Hooley et al., 2005) argue that organizational success depends on employees who are far away from the top level strategists. At the same time they are not typically within the direct supervision of the marketing departments. In this way, since these are the workers having direct contact with external customers and therefore are responsible for the offered service quality, internal marketing practices focusing on organizational commitment are of prime importance to service organizations.

As far as HCIs are concerned, health workers' commitment is highly valuable because committed health workers will identify with the goals and values of the institution, has a stronger desire to belong to the organization and are willing to display greater organizational citizenship behavior i.e., a willingness to go over and beyond their required job duties. If human resources are the major assets of organizations, then committed human resources are supposed to be organization's competitive advantage (Katz \& Kahn, 1977). Lack of organizational commitment affects job performance (Luchak \& Gellatly, 2007), becomes a cause of absenteeism (Kumar \& Eng, 2012), and turnover (Price \& Mueller, 1981; Jehanzeb et al, 2013). It is a hindrance for attainment of organizational goals and damages the reputation and goodwill of HCIs. In Ethiopia however, in addition to the problem of brain drain (Yifru, 2007), experiences show short tenure of achievement oriented health workers (Hailu et al., 2013). Moreover, there is alarming turnover rate, weak organizational commitment of Medical Doctors in particular (HSDP, 2011) and delay at work (Kassa, et al., 2011). Therefore, health workers' organizational commitment needs a due attention of management in HCIs of Ethiopia. Internal marketing components (i.e. i.e. implementation of specific corporate or functional strategies and vision, employee development and employee reward) improves employee commitment and, in turn, it is essential for improvement of service quality and thereby external customers' satisfaction. As per the researcher's understanding, these variables might not be rigorously researched in the context of Ethiopian HCIs.

Hence, this research attempts to analyze how the different components building up internal marketing (i.e. implementation of specific corporate or functional strategies and vision, employee development and employee reward) are implemented in the selected hospitals and their role to organizational commitment of health workers.

\subsection{Research Questions}

1. What is the relationship between health workers' understanding of organizational vision and organizational commitment?

2. What is the effect of development on commitment of health workers?

3. To what extent does reward influence organizational commitment of health workers?

\subsection{Objectives of the study}

\subsection{General objective}

As main objective, this study aimed at investigating the effect of Internal Marketing on Organizational Commitment of health workers in Heath Care Institutions.

\subsubsection{Specific Objectives}

The following points can be worth mentioned as specific objectives of this study:

- To identify the relationship between health workers' understanding of organizational vision and organizational commitment.

- To determine the effect of development on commitment of health workers.

- To examine the influence of reward on organizational commitment of health workers.

\subsection{Scope of the study}

The concept of internal marketing is broad and it can be influenced by various factors. But in this study those internal marketing aspects (i.e. implementation of specific corporate or functional strategies and vision, employee development and employee reward) are considered because they are pointed out as the major determinants of internal marketing by different researchers (e.g. Foreman and Money, 1995; Quester and Kelly, 1999; Ahmad and 
Rafiq, 2002; Farzad et al., 2008; Abzari, 2011). These variables are considered to be the main elements of internal marketing. Other variables which might affect internal marketing are not considered in this study. Thus, this study investigated the effect of internal marketing on organizational commitment of health workers in the context of Ethiopian HCIs by selecting Yirgalem, Hawassa Referral \& Adare Hospitals based on their convenience to the researcher. Cross-sectional data was collected using structured questionnaire from October 2017 to November 2017 and the data analyzed inferentially. The sample respondents were taken from the health workers of the hospitals that are permanent workers and have served for at least 1 year.

\subsection{Significance of the study}

Internal marketing and organizational commitment are a reflection of effectiveness in both human resource management and marketing management. This study tried to investigate the extent to which the management of the selected hospitals are marketing oriented then, to what extent the health workers are committed as well. More specifically, the study examined the relationship between the selected facets of internal marketing and health workers' commitment to stay at their institutions and exert high level of effort. Given this description, the top management of the institution may have a direction to investigate the level of organizational commitment of their health workers, which can signal what activities to run in order to enhance the commitment of health workers. Moreover, this study can help the management of the selected hospitals in particular and Ethiopian HCIs in general to take measures towards increasing marketing orientation and develop organizational commitment of health workers thereby maintaining patients and community satisfaction. Finally this study will also provide insight to other researchers for further investigation on the field of internal marketing.

Fig. 1.1 Conceptual Framework of the study

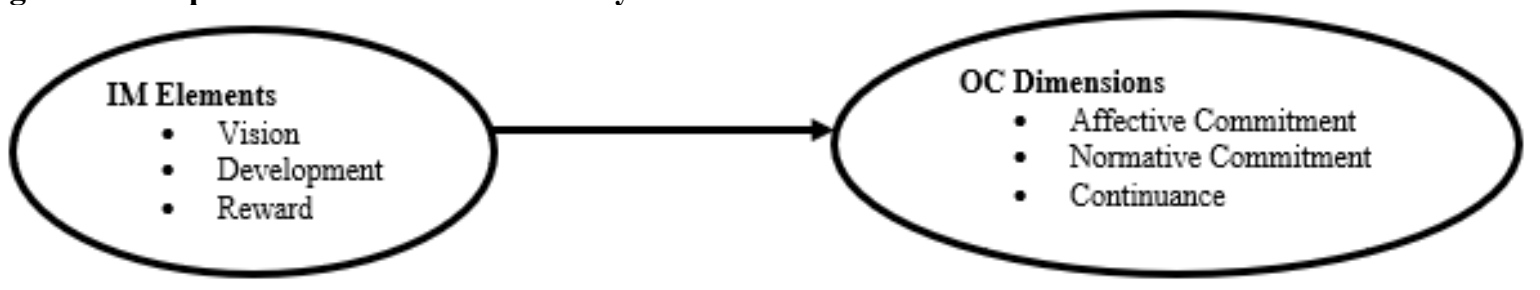

Source: Own construction, 2015

\section{MATERIALS AND METHODS}

In this section, the researcher made a detailed discussion of the design of the research, the population of the study, sampling design of the study, sources of data, instruments and measurement of variables in the study, data collection procedures, methods of data editing and analysis, and ethical considerations.

\subsection{Research Design}

In this study explanatory research design is used and hence, quantitative data was collected mostly through primary sources to find empirical evidenced from about the effect of internal marketing elements on organizational commitment of health workers in Ethiopia. The researcher used valid surveys designed to answer the research questions.

\subsubsection{Study population}

The population of this study consists of health workers of the three selected hospitals. The samples will be drawn from all the selected hospitals on proportional basis. According to the semi-annual human resource reports of the three selected hospitals- Sept 2014/15, the total numbers of health workers is presented in the following table:

Table 1: Study population and their proportions

\begin{tabular}{lcc}
\hline Hospital's Name & $\mathrm{N}$ & $\%$ \\
\hline Adare Hospital & 216 & 18 \\
Yirgalem Hospital & 365 & 30 \\
Hawassa University College of Health Sciences & 635 & 52 \\
Total & $\mathbf{1 2 1 6}$ & $\mathbf{1 0 0 \%}$ \\
\hline
\end{tabular}

\subsubsection{Sampling Design}

Source: Survey Data, 2015

The sampling technique employed in this study for quantitative survey is probabilistic sampling technique because it is more commonly associated with survey based research. When the population to be sampled is not homogenous and consists of several subgroups, stratified sampling may give a more representative sample than simple random sampling. The population of this study is not homogenous because of differences in educational background, physical environment, institutional conditions, etc. Thus, stratified sampling is used to select the target employees from all the three hospitals (namely Adare Hospital, Hawassa Referral Hospital, Yirgalem Hospital) and further 
categorization was made as Medical Doctors, Other health workers and administrative workers. Thereafter, from each stratum, respondents were selected by the convenience sampling technique on proportion basis. Convenience sampling used because some health workers like medical doctors may be busy for access due to the nature of their job.

Table 2: Proportions of Respondents According to their Profession

\begin{tabular}{lccc} 
& Medical Doctors & Other Health Workers & Support Staff \\
\hline Adare Hospital & 17 & 163 & 36 \\
HU Referral Hospital & 65 & 359 & 211 \\
Yirgalem Hospital & 23 & 215 & 127 \\
Total & 105 & 737 & 374 \\
\hline
\end{tabular}

\subsubsection{Sample Size}

Source: Survey Data, 2015

A sample size which is more representative to each hospital's workers was taken and it was considered large enough to allow for precision, confidence and generalizability of the research findings. The researcher employed a sample size determination formula developed by Jeff Watson (2001). Accordingly, 370 respondents were selected as a sample from the total population of 1216 health workers.

Finally, proportional samples were taken from all stratums as follows:

Table 3: Sample of the study by Hospital

\begin{tabular}{lccc}
\hline Hospital's Name & $\mathrm{N}$ & $\mathbf{\%}$ & $\mathrm{n}$ \\
\hline Adare Hospital & 216 & 18 & 67 \\
Yirgalem Hospital & 365 & 30 & 111 \\
Hawassa University College of Health Sciences & 635 & 52 & 192 \\
Total & $\mathbf{1 2 1 6}$ & $\mathbf{1 0 0 \%}$ & $\mathbf{3 7 0}$ \\
\hline
\end{tabular}

Source: Survey Data, 2015

Table 4: Sample of the study by Staff diversity

\begin{tabular}{lccccccccc}
\hline & \multicolumn{1}{c}{ Adare Hospital } & \multicolumn{3}{c}{ HU Referral Hospital } & \multicolumn{3}{c}{ Yirgalem Hospital } \\
\hline & $\boldsymbol{N}$ & $\boldsymbol{\%}$ & $\boldsymbol{n}$ & $\boldsymbol{N}$ & $\boldsymbol{\%}$ & $\boldsymbol{n}$ & $\boldsymbol{N}$ & $\boldsymbol{\%}$ & $\boldsymbol{n}$ \\
Medical Doctors & 17 & 8 & 6 & 65 & 10.2 & 20 & 23 & 6 & 7 \\
Other Health Workers & 163 & 75 & 50 & 359 & 56.2 & 109 & 215 & 59 & 65 \\
Support Staff & 36 & 17 & 11 & 215 & 33.6 & 63 & 127 & 35 & 39 \\
Total & 216 & 100 & 67 & 639 & 100 & 192 & 365 & 100 & 111 \\
\hline
\end{tabular}

\subsubsection{Sources of Data}

Source: Survey Data, 2015

To realize the objective of this study, data were collected from both primary and secondary sources. Both primary and secondary data from respective sources are discussed in this section.

\subsubsection{Primary Data}

Primary data was obtained directly from the sample respondents by use of questionnaires.

\subsubsection{Secondary Data}

Secondary data was sourced from a review of related literature from books, journals, hospitals institutional reports, and published articles.

\subsubsection{Instruments and Measurement of variables}

In this research the instruments for data gathering was questionnaire. The variables of this research are of two types: independent and dependent. Accordingly, internal marketing is independent variable and organizational commitment is dependent variable. To measure these variables two sets of questionnaires namely: internal marketing and organizational commitment questionnaires were used.

To gather relevant information regarding each aspect of internal marketing and organizational commitment, the researcher used valid questionnaires. To measure the aspects of internal marketing, the researcher use adapted 15 items internal marketing measuring instrument developed by (Foreman and Money, 1995). Organizational commitment was measured using the three-dimensional (Meyer, Allen \& Smith, 1993) instrument originally developed by (Allen \& Meyer, 1990). Accordingly, a five- point likert-type scale ranging from "Strongly agree" to

"Strongly disagree" was used for both types of questionnaires. The affective, continuance and normative organizational commitment scal es each comprised eight items, a total of 24 items.

\subsubsection{Data Collection Procedure}

The demographic, internal marketing and organizational commitment questionnaires were distributed to the respondents. The researcher used enumerators to individually hand out questionnaires to respondents. A cover 
letter which explains the purpose of the study and its approval was attached to the questionnaire, which also gave explanation about ethical considerations such as anonymity of respondents and confidentiality of the responses.

\subsubsection{Processing and Analysis of Data}

The collected data was edited, coded and classified for ease of processing and analysis in Statistical Packages for Social Sciences (SPSS) software version 20. All the questionnaires from the respondents were properly and carefully scrutinized so as to check on the omissions, incomplete responses and inconsistencies. By analyzing the data, the researcher has made an attempt to determine if there is a linear correlation and interdependence between internal marketing and organizational commitment through the use Pearson's Correlation.

The researcher also employed multiple linear regressions because it allowed examining the effect of multiple independent variables on the dependent variable. Thus, the researcher has run linear regressions by taking combined effect of internal marketing elements (i.e. vision, development and reward) as independent variables and the cumulative of organizational commitment dimensions (i.e. affective commitment, continuance commitment and normative commitment) as dependent variable.

\section{Model Specification}

In order to examine the relationship between the dependent variables and independent variables, the following multiple linear regression model was applied.

$\mathrm{Y}_{1}=\beta_{01}+\beta_{11} \mathrm{X}_{1}+\beta_{21} \mathrm{X}_{2}+\beta_{31} \mathrm{X}_{3}+\mathrm{e}_{1}$

$Y_{2}=\beta_{02}+\beta_{12} X_{1}+\beta_{22} X_{2}+\beta_{32} X_{3}+e_{2}$

$\mathrm{Y}_{3}=\beta_{03}+\beta_{13} \mathrm{X}_{1}+\beta_{23} \mathrm{X}_{2}+\beta_{33} \mathrm{X}_{3}+\mathrm{e}_{3}$

Where:

$\mathrm{Y}_{1}, \mathrm{Y}_{2}, \mathrm{Y}_{3}=$ the explained variables $(\mathrm{AOC}, \mathrm{COC}, \mathrm{NOC})$

$\mathrm{X}_{1}, \mathrm{X} 2, \mathrm{X}_{3}=$ the independent variables (vision, development, reward)

$\mathrm{e}=$ error term

\section{RESULTS AND DISCUSSIONS}

Table 7: Pearson's Correlation Analysis

\begin{tabular}{llccc}
\hline & & AOC & COC & NOC \\
\hline $\boldsymbol{I M}$ & Pearson Correlation & $.399^{* *}$ & $.427^{* *}$ & $.983^{* *}$ \\
& Sig. (2-tailed) & .000 & .000 & .000 \\
& $\mathrm{~N}$ & 302 & 302 & 302 \\
\hline
\end{tabular}

*. Correlation is significant at the 0.05 level (2-tailed).

**. Correlation is significant at the 0.01 level (2-tailed).

Source: Survey Data, 2015

As clearly shown on Table 7, there is significant and positive relationship between IM and OC dimensions. Positive and strong relationship was found between internal marketing and dimensions of organizational commitment $(\mathrm{r}=0.399, \mathrm{p}<.01)$, suggesting that as the presence of internal marketing activities increases within a firm, so too does the likelihood that affective organizational commitment will also be present. Also strong and very strong positive relationships exist between internal marketing and continuance organizational commitment $(\mathrm{r}=.427, \mathrm{p}<.01)$ and internal marketing and normative organizational commitment $(\mathrm{r}=.983, \mathrm{p}<.01)$ respectively.

Table 8: Regression Model Summary

\begin{tabular}{lcccc} 
Model & $\mathrm{R}$ & R Square & Adjusted R Square & Std. Error \\
\hline 1 & $.854^{\mathrm{a}}$ & .730 & .729 & .13322 \\
\hline a. Predictors: (Constant), IM & & & \\
\hline
\end{tabular}

Source: Model Estimation based on the survey data, 2015

As Table 8 illustrates, linear regression was then used to examine the actual amount of explanation provided by combined internal marketing to organizational commitment. The R-Square value in the model summary depicts the degree of variance in the dependent variable which is explained by the model. The R-square value of .729 indicates that the internal marketing construct explains $72.9 \%$ of the variance in employee commitment. In other words, the result has showed internal marketing aspects predict organizational commitment by $72.9 \%$. This implies the presence of internal marketing activities in health care institutions may drastically increase commitment of health workers. 
Table 9: Regression Coefficients

\begin{tabular}{|c|c|c|c|c|c|c|}
\hline \multirow{2}{*}{\multicolumn{2}{|c|}{ Model }} & \multicolumn{2}{|c|}{ Unstandardized Coefficients } & \multirow{2}{*}{$\begin{array}{c}\begin{array}{c}\text { Standardized } \\
\text { Coefficients }\end{array} \\
\text { Beta }\end{array}$} & \multirow[t]{2}{*}{ t-value } & \multirow[t]{2}{*}{ Sig. } \\
\hline & & $B$ & Std. Error & & & \\
\hline \multirow[t]{4}{*}{1} & (Constant) & 2.821 & .183 & & 15.427 & .000 \\
\hline & Vision & .094 & .041 & $.131 * *$ & 2.290 & .023 \\
\hline & Development & -.105 & .056 & -.126 & -1.867 & .063 \\
\hline & Reward & .134 & .039 & $.203 * * *$ & 3.438 & .001 \\
\hline
\end{tabular}
in predicting the organizational commitment. In this case the most important predictors are reward (Beta $=0.203$ ) and vision (Beta $=0.131$ ). Deviating from most literature, in this study there is no significant relationship between development and organizational commitment. The result of this study implies that, most of the HR managers and even marketing experts don't have understanding about the concept of internal marketing. They are considering the aspects of IM as simple HR practices. The study further indicated that staff development is not a way to keep experienced staff unless the staff is envisioned and provided with challenging goals on progressive basis. Otherwise developed staff looks for other organization to find new opportunities.

\section{CONCLUSIONS AND RECOMMENDATION}

The main objective of the study was to examine the effect of internal marketing on organizational commitment of health workers in selected hospitals of Sidama Zone. The results showed that internal marketing strongly affects organizational commitment and this finding is consistent with findings of other researchers. Caruana and Calleya (1998) assured that there is strong positive relationship between IM and OC. Also studies conducted in banks and hotels mostly in Iran and Nigeria found significant positive relationship between aspects of IM and OC dimensions (eg. Lings 2004; Farzad et al. 2008; Abzari 2011; Hooshmand 2012; Kaurav et al. 2015). Hence the following recommendations are suggested:

- Designing and implementing performance based reward systems incorporating both financial and non-financial benefits are important factors to increase commitment of health workers.

- Workers need to be envisioned and empowered to involve in decision making particularly about the goals and mission of the HCIs.

- Staff development practices should be aligned to the strategic goal and vision of the organization along with advancement of the entire institution.

However, in order to generalize the results of this study, it needs replicated in different service settings in the context of Ethiopia. Further exploration of the concept and measure of internal marketing are also recommended as future research directions.

\section{References}

Aburoub, A. S., Hersh, A. M., \& Aladwan, K. (2011). Relationship between Internal Marketing and Service Quality with Customers' Satisfaction. International Journal of Marketing Studies, 3(2).

Ahmed, P. K., Rafiq, M., \& Saad, N. M. (2003). Internal marketing and the mediating role of organizational competencies. European Journal of Marketing, 37(9), 1221-1241.

Allen, N. J., \& Meyer, J. P. (1990). The measurement and antecedents of affective, continuance and normative commitment to the organization. Journal of occupational psychology, 63(1), 1-18.

Carlos, V. S. \& Ricardo, G. R. (2012). Internal Market Orientation in Higher Education Institutions--its InterRelations with other Organizational Variables. Viesoji Politika ir Administravimas 11.4.

Grönroos, C. (1980). Designing a long range marketing strategy for services. Long Range Planning, 13(2), 36-42.

Grönroos, C. (1981). Internal marketing an integral part of marketing theory in marketing of services. Edited by Donnelly JH Jr., George WR. Chicago: American marketing Association; pp. 236-238.

Hailu, A., Mariam, D. H., Fekade, D., Derbew, M., \& Mekasha, A. (2013). Turn-over rate of academic faculty at the College of Health Sciences, Addis Ababa University: a 20-year analysis (1991 to 2011). Human Resources for Health, 11(1), 61.

Hartline, M. D., \& Bejou, D. (2004). Internal relationship management: Linking human resources to marketing performance. Journal of Relationship Marketing, 3(2-3), 1-4.

Katz, D., Kahn, R. L. (1978). The Social Psychology of Organizations. New York: Wiley

Kotler, P. (1967). Managerial Marketing, Planning, Analysis, and Control. Englewood Cliffs. 
Kotler, P., Fahey, L., \& Jatusripitak, S. (1985). The new competition: What theory Z didn't tell you about marketing. Prentice Hall.

Kotler, P. A. Gary. 2008. Principles of Marketing, 5.

Luchak, A. A., \& Gellatly, I. R. (2007). A comparison of linear and nonlinear relations between organizational commitment and work outcomes. Journal of Applied Psychology, 92(3), 786.

Malhotra, N., \& Mukherjee, A. (2004). The relative influence of organizational commitment and job satisfaction on service quality of customer-contact employees in banking call centers. Journal of Services Marketing, $18(3), 162-174$.

Money, A. H., \& Foreman, S. (1996). The measurement of internal marketing: a confirmatory case study. Journal of Marketing Management, 11(8), 755-766.

Price, J. L., \& Mueller, C. W. (1981). Professional turnover: the case of nurses. Health systems management, 15, 1.

Rafiq, M., \& Ahmed, P. K. (2000). Advances in the internal marketing concept: definition, synthesis and extension. Journal of services marketing, 14(6), 449-462.

The Federal Democratic Republic of Ethiopia (2010) Health sector development program 2010/2011-2014/2015.

Berry, L. L. (1980). Services marketing is different. Business, 30(3), 24-29.

Berry, L. L., \& Allen, B. H. (1977). Marketing's crucial role for institutions of higher-education. Atlanta Economic Review, 27(4), 24-31.

Bennett, R., \& Barkensjo, A. (2005). Internal marketing, negative experiences, and volunteers' commitment to providing high-quality services in a UK helping and caring charitable organization. Voluntas: International Journal of Voluntary and nonprofit organizations, 16(3), 251-274.

Berry, L. L. (1995). Relationship marketing of services-growing interest, emerging perspectives. Journal of the Academy of marketing science, 23(4), 236-245.

Naudé, P., Desai, J., \& Murphy, J. (2003). Identifying the determinants of internal marketing orientation. European Journal of Marketing, 37(9), 1205-1220.

Gounaris, S. P. (2006). Internal-market orientation and its measurement. Journal of business research, 59(4), 432448.

Semela, T. (2004). Perceptions of Work Environment in Ethiopian Higher Learning Institutions: A Search for Antecedents of Organizational Commitment and Turnover among Debub University Instructors. The Ethiopian Journal of Higher Education, 1(2), 33-60.

Hooley, G. J., Greenley, G. E., Cadogan, J. W., \& Fahy, J. (2005). The performance impact of marketing resources. Journal of business research, 58(1), 18-27.

Kumar, R., \& Eng, K. G. (2012). Perceived organizational commitment and its impact to the turnover intention: a correlation analysis. Journal of global business and economics, 4(1), 40-57.

Jahanzeb, S., Fatima, T., \& Mohsin Butt, M. (2013). How service quality influences brand equity: The dual mediating role of perceived value and corporate credibility. International Journal of Bank Marketing, 31(2), 126-141.

Berhan, Y. (2008). Medical doctors profile in Ethiopia: production, attrition and retention. In memory of 100-years Ethiopian modern medicine \& the new Ethiopian millennium. Ethiopian medical journal, 46, 1-77.

Quester, P. G., \& Kelly, A. (1999). Internal marketing practices in the Australian financial sector: an exploratory study. Journal of Applied Management Studies, 8(2), 217.

Farzad, A., Nahavandi, N., \& Caruana, A. (2008). The effect of internal marketing on organizational commitment in Iranian banks.

Abzari, M., Ghorbani, H., \& Madani, F. A. (2011). The effect of internal marketing on organizational commitment from market-orientation viewpoint in hotel industry in Iran. International Journal of Marketing Studies, 3(1), 147.

Watson, J. (2001). How to determine a sample size: Tipsheet\# 60. University Park, PA: Penn State Cooperative Extension.

Meyer, J. P., Allen, N. J., \& Smith, C. A. (1993). Commitment to organizations and occupations: Extension and test of a three-component conceptualization. Journal of applied psychology, 78(4), 538.

Caruana, A., \& Calleya, P. (1998). The effect of internal marketing on organisational commitment among retail bank managers. International Journal of bank marketing, 16(3), 108-116.

Lings, I. N. (2004). Internal market orientation: Construct and consequences. Journal of Business Research, 57(4), 405-413.

Vazifehdoost, H., Hooshmand, S., \& Dehafarin, E. (2012). The effects of internal marketing and organizational commitment on bank's success. International Journal of Business and Commerce, 1(9), 1-15.

Kaurav, R. P. S., Paul, J., \& Chowdhary, N. (2015). Effect of internal marketing on hotels: Empirical evidence for internal customers. International Journal of Hospitality \& Tourism Administration, 16(4), 311-330. 